\title{
A ESCRITA WAIMIRI-ATROARI, UMA ETNOGRAFIA DA ETNOLOGIA INDÍGENA: MEMÓRIAS E A CONSTRUÇÃO SOCIAL DA RESISTÊNCIA ${ }^{1}$
}

Eduardo Gomes da Silva Filho ${ }^{2}$

\begin{abstract}
RESUMO
O objetivo do presente trabalho é abordar a partir de uma experiência etnográfica vivida por um casal de missionários ligados à igreja católica entre os anos de 1985 e 1986 junto aos índios Waimiri-Atroari na aldeia Yawará em Roraima, a produção de fontes escritas baseadas na reconstrução da memória e alguns relatos orais deste grupo. No âmbito da história, ainda são escassos, até o presente momento, no Brasil estudos relacionados com mais profundidade a essa temática, ainda distante de se pretender chegar a uma resposta definitiva sobre essa questão, o texto objetiva ressaltar alguns aspectos teóricos e metodológicos relacionados ao trabalho dos missionários, que se basearam no método de Paulo Freire para tentar alfabetizar os indígenas, além disso, os relatos orais feitos anos depois por um dos missionários corroboraram com as memórias da época, onde os índios produziram um novo tipo de fonte, baseados em uma fatídica experiência genocida vivida por eles durante o regime civilmilitar, mas que demonstrou a organização social do grupo, além de caracterizar-se como uma forma de resistência cultural.
\end{abstract}

\section{PALAVRAS-CHAVE}

Índios Waimiri-Atroari. Memória. Trabalho missionário. Resistência.

\begin{abstract}
A gente desenvolveu esse trabalho em um método mais Paulo Freire, né, a partir do desenho, em que eles mesmos se sentissem donos, ser criadores do seu alfabeto, e a partir desse alfabeto também criar ou recompor a sua própria História, a sua Geografia, toda sua [...] tudo começou a aparecer ali, né? E aí também, né, iniciou a história deles, não é? Começou a contar com desenhos, e escrevendo, em 4 meses tinham uns 10 que já escreviam frases na língua deles, né? Apesar de que quando nós chegamos lá não imaginavam que a sua língua pudesse ser escrita. Queriam é aprender português. É. Mas quando a gente mostrou, colocou no meio os desenhos deles começaram a sair [...] surgir às letras, e aí eles ficaram todo entusiasmados. Nos primeiros4 meses ninguém perguntou mais do Português (SCHWADE, 2013).
\end{abstract}

"É no caminho da crítica histórica que a memória encontra o sentido da justiça" (RICOEUR, 2007, p. 507). As palavras de Paul Ricoeur nos serviram de estímulo para que nós tentássemos recuperar a partir de uma experiência etnográfica vivida pelo casal de missionários Egydio e Doroti Schwade junto aos índios Waimiri-Atroari, entre os anos de 1985 e 1986 a história de resistência desse povo. Nessa ótica, a formação dessa memória só se fez possível, em razão da demonstração cultural dos seus costumes e tradições. Deste modo, as formas de organização social e cultural desse povo estão intrinsecamente ligadas a sua própria cosmologia. Acerca da experiência, Egydio Schwade comentou:

Olha, ela aconteceu em 1985 e 86, né? Nós estivemos lá um ano e meio, aproximadamente, né? E foi uma experiência das mais ricas da minha vida, né? Porque, inclusive, assim, é [...] eu tinha ouvido muito, não é? Inclusive eu vim com a família para cá exatamente para tomar esse contato porque eu sempre [...] durante os anos anteriores em que eu fui também Secretário Executivo no CIMI Nacional durante 7 anos, que foi [...] eu sempre escutei, né, todo o sofrimento desse povo, né? E a maneira brutal com que foi tratado, não é, pelo Exército e com o apoio sempre da FUNAI, na época. E principalmente também essa apresentação deles ao público, sempre como assassinos e funcionários da FUNAI, como assassinos de todo mundo que entrasse lá, né, e tal. Então como terroristas. Aí como os americanos tratam todo mundo contra eles, terroristas semelhantemente era, então, os maiores terroristas do país eram os Waimiri-Atroari. Aí então eu tinha certeza de que isso, isso é um mito criado pela FUNAI contra esse povo, não é? E que tinha que ser desmanchado, né? E aí nós $[\ldots]$ quando eu cheguei aqui no [...] me estabeleci aí, quando eu me estabeleci aqui no norte, iniciei lá em Itacoatiara, ficando à distância, né? Porque eu era proibido, na época, pelos militares, de entrar em qualquer área indígena do país. E isso... e então eu não queria, assim, provocar de cara isso, né? Isso. E aí então, nós, eu e a minha esposa, começamos um processo de cercar. Primeiro ela começou pelo Rio Negro, tomar contatos de como é que a gente pudesse se aproximar de alguma aldeia, né? Aí depois fizemos por Roraima, conhecer tudo em volta, né? Daí, viemos pelo rio Uatumã quando Balbina não existia, quer dizer, estavam começando, tinham desviado, tinha uma ilhazinha no meio, e tinha desviado as águas para um lado da ilha, né? E aí a gente chegou ali e viu [...], ficamos observando depois então já começamos com a família toda, né? A tomar contato. Aliás, a maior parte do

1 Originalmente, apresentado no XXVIII Simpósio Nacional de História - Anpuh, realizado na cidade de Florianópolis, em 2015.

2 Mestre em História Social, Professor da Educação Básica vinculado ao Centro de Mídias e Tecnologias da Secretaria de Educação do Estado do Amazonas e Membro do Grupo de Pesquisa de História do Trabalho da Universidade Federal do Amazonas. 
tempo [...], quando já para tomar contato sempre nos apresentamos como a família toda, crianças pequenas, o Adu era pequenininho, né, tinha 3 anos; não, 4 anos. O Agioli, o mais velho, tinha 5, 6 , né, uns 5 anos. Mas quando fizemos os contatos ainda menos, 1 ou 2 anos eram pequenos. Mas assim mesmo a gente ia com a família, né? Primeiro começamos pelo sul e depois um padre, dois padres, né, de uma paróquia de São Luís do Anauá, nos a [...] a gente fazia um trabalho conjunto, eu ajudava na catequese, lá na paróquia dele, um pouco eu e a minha esposa. E nos cursos de formação, do pessoal. E ele então nos apoiou com o carro (SCHWADE, 2013).

O início dessa experiência relatada acima por Egydio, remonta parte da sua estratégia para conviver com os índios, onde o missionário nos retratou com riqueza de detalhes e com um semblante que transbordava emoção, essa experiência missionária, que ele vivenciou com a sua própria família. Essas narrativas denotam, também, além do seu relacionamento com os índios, o cotidiano com os funcionários da FUNAI, alguns conflitos, e as práticas de resistência indígena que Egydio teve a oportunidade de presenciar pessoalmente, como ele mesmo relatou acima. No entanto, antes de entrarmos nesta discussão, tentamos reconstituir a trajetória anterior do casal Schwade à entrada na aldeia Waimiri-Atroari, como citou Egydio em um dos seus artigos publicados no Blog da Casa da cultura do Urubuí no ano de 2013.

Em 1978 nos casamos. Naquele momento eu era então Secretário Executivo do CIMI Nacional, cujo trabalho continuamos até 1980. Naquele ano viemos, a convite de Dom Jorge Marskell, bispo da Prelazia de Itacoatiara/AM, assumir a Pastoral Indígena desta Prelazia, em especial para iniciar um trabalho junto ao povo Waimiri-Atroari. A tarefa foi muito difícil por conta do bloqueio, da perseguição e da difamação perpetrada por agentes da Ditadura Militar e de gananciosos que promoviam o extermínio daquele povo para se apossar e expropriar o território. Doroti e eu nos localizamos primeiro na sede da Prelazia, em Itacoatiara, inserindo-nos na Pastoral, fazendo levantamentos no entorno da área Waimiri-Atroari e fazendo contatos com algumas aldeias, mesmo estando proibidos pelos Ditadores. Para permanecer mais próximos da área indígena estabelecemo-nos, no inicio de 1984 no recém-criado município de Presidente Figueiredo. Com o fim da Ditadura Militar fomos convidados pelos índios e autorizados pela FUNAI a participar da vida em suas aldeias, iniciando o primeiro trabalho de alfabetização em sua língua materna. Pela primeira vez o povo Waimiri-Atroari ou Kiña, como se autodenominam, começou a revelar o que lhe aconteceu durante a Ditadura Militar (SCHWADE, 2013, p. 1).

Nessa ótica, o missionário nos forneceu os elementos necessários para que nós compreendêssemos o período que antecedeu sua entrada na Terra Indígena, assim como nos alertou para a política do regime civil-militar com os índios. No entanto, ainda tomando como base o seu depoimento, podemos observar que ele obteve uma autorização para entrar na aldeia, a sua intenção sempre foi à defesa dos direitos dos povos indígenas, e naquele momento, ele estava imbuído de alfabetizá-los em sua própria língua materna.

Para que isso fosse possível, inicialmente foi criado um grupo de estudos através da Portaria n. 1898 de 03 de julho de 1985, que segundo o documento, reuniu a convite da FUNAI uma série de indigenistas para discutir a relação conflituosa entre os índios e seus servidores, além de assuntos relacionados aos projetos de mineração e da construção a Hidrelétrica de Balbina. Porém, como consta no documento, um dos seus principais objetivos era tentar achar uma maneira de "acalmar" os índios.

Essa missão dada pela FUNAI ficou a cargo do sertanista José Porfírio Fontenele de Carvalho, que na época era assessor da presidência da FUNAI, do Delegado da $1^{\text {a }}$ Diretoria Regional, Sebastião Amâncio, do Antropólogo Paulo Heringer Filho, do técnico indigenista Egypcio Nunes Correia, do advogado do CIMI Felisberto Damasceno, do antropólogo da UnB Stephen Grant Baines, e do indigenista e missionário do CIMI Egydio Schwade. Isso pode ser confirmado a partir da fala do próprio Egydio, que nos relatou como se deu parte deste processo.

E entrou um presidente que começou, inclusive, um primeiro programa, né? Foi esse de fazer, de mudar a política indigenista dos Waimiri-Atroari. E ele criou o grupo de estudos e trabalho, né, integrado por diversas coisas, Stephen Baines que integrou, eu, Doroti, minha esposa, a nossa família foi 
toda junto, e mais alguns funcionários da FUNAI, um advogado do CIMI, e assim era uma equipe bem diversificada, né? E aí nós realmente reorganizamos assim uma proposta de trabalho nova, né, que iniciou exatamente na aldeia lá de (Yawará) lá que a gente depois iniciou também, o projeto de alfabetização na língua deles, não é? E isso foi então em meados de 1985, né, que foi decidido nessa reunião essa ida nossa para lá. E foi realmente, foi [...] bom (SCHWADE, 2013).

Após a consolidação do grupo de estudos e trabalhos criado pela FUNAI, o casal de missionários iniciou suas atividades na aldeia Yawará, onde procurou articular a alfabetização na língua materna Waimiri-Atroari com um trabalho de valorização das memórias recentes desse povo. De acordo com Egydio, a experiência começara de forma fascinante, com intensa participação dos índios, no entanto, algumas críticas às condições do prédio foram feitas pelo casal de missionários como veremos abaixo:

Mal havíamos dado os nossos primeiros passos na aldeia, quando fomos levados para dentro da escola, sem sequer termos tempo para preparar a $1^{\mathrm{a}}$ aula, tal era a exigência dos índios e a situação de frustração frente a um prédio escolar que há mais de um ano decaia sem aproveitamento algum, apesar da grande vontade de terem aula. (SCHWADE; MÜLLER, 1986, p. 4).

De acordo com Egydio, a vontade dos índios em participar das aulas surgira a partir da necessidade que eles tinham de evidenciar as atrocidades cometidas pelos militares aos seus antepassados. Isso de fato desagradou a FUNAI, que não queria ter a sua imagem associada às práticas genocidas do Estado brasileiro frente aos índios. Na realidade, com a evidência das memórias, os índios buscavam de alguma forma alertar a sociedade civil de tais práticas, partindo das ações de organização social do grupo. Por outro lado, o contato interétnico facilitou essas pretensões, na medida em que a relação dos índios com os missionários era harmoniosa, fato que pode ser percebido a partir da figura abaixo, onde podemos observar o início dos trabalhos de alfabetização de Egydio Schwade, no ano de 1985 junto aos índios Waimiri-Atroari na aldeia Yawará em Roraima.

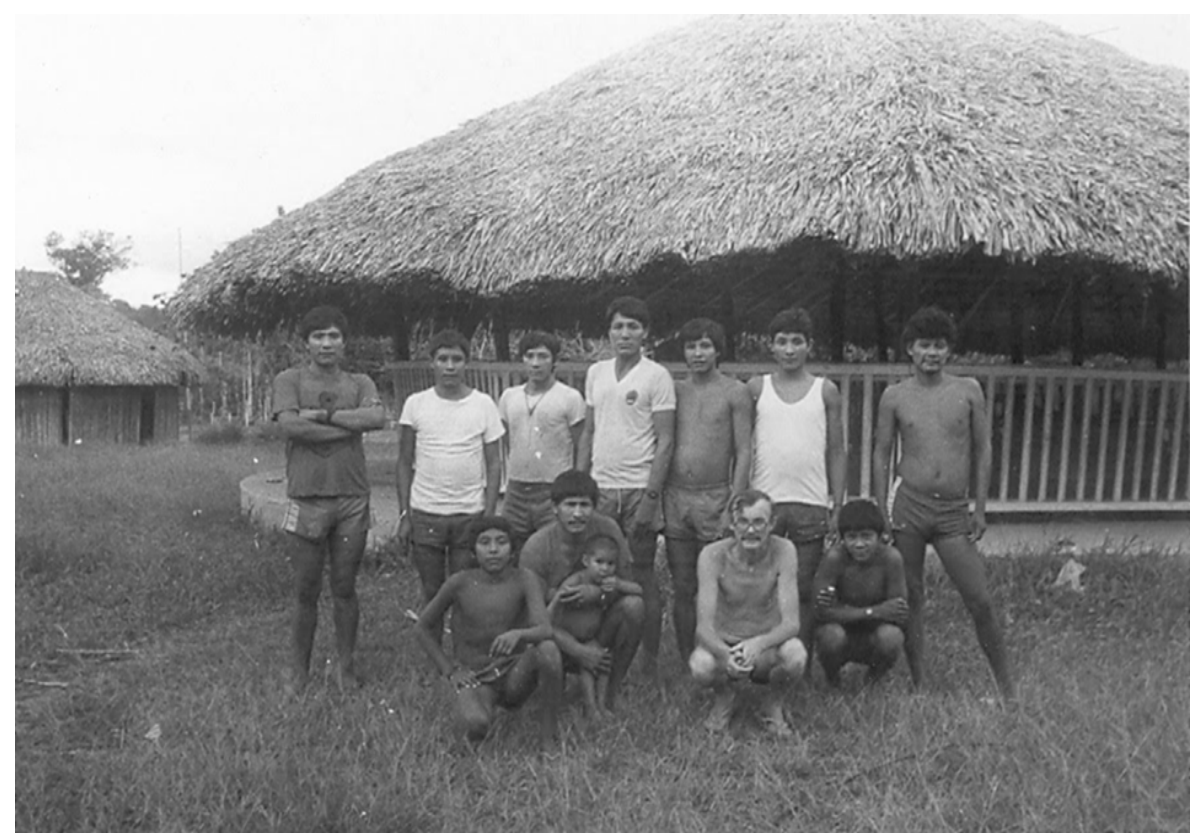

Figura 01: Egydio Schwade na aldeia Yawará com os índios Waimiri-Atroari em 1985.

Fonte: Arquivo pessoal da família Schwade.

Aos poucos os índios foram colocando alguns desenhos na lousa, fazendo emergir representações do cotidiano e de seus mitos, além das memórias da sua história recente, e, sobretudo em relação à ação dos militares e das empresas que devastaram o seu território. Toda a violência sofrida pela comunidade Waimiri-Atroari no período militar, constitui-se, por assim dizer, num dos topos da memória coletiva desse povo. A proposta do grupo de trabalho era criar condições para que essas memórias aflorassem no âmbito do grupo e - mediante um trabalho de tradução - repercutissem no espaço público, permitindo uma politização da questão desse povo. 
Assim, os relatos dos próprios índios sobre as práticas de genocídio a que foram submetidos, surgiram através de desenhos, letras, depoimentos e descrições, realizadas nas aulas de alfabetização, e podia significar em um reforço dos vínculos étnicos, na medida em que reafirmavam o pertencimento do grupo em meio às agressões por parte do Estado brasileiro. Contudo, o material produzido também permitia apresentar a sociedade nacional e mesmo no âmbito de fóruns internacionais, os povos Waimiri-Atroari enquanto vítimas de uma guerra de extermínio movida pelo Estado em beneficio das grandes empresas.

Um dos sobreviventes, o índio Panaxi, habitante de uma aldeia do rio Alalaú, disse, que durante a construção da BR 174 seu pai, mãe, irmãos, parentes e amigos foram atacados por aviões, helicópteros, bombas, metralhadoras, fios elétricos e estranhas doenças, comunidades inteiras desapareceram depois que helicópteros de soldados sobrevoaram ou pousaram em suas aldeias. Nas palavras de Panaxi:

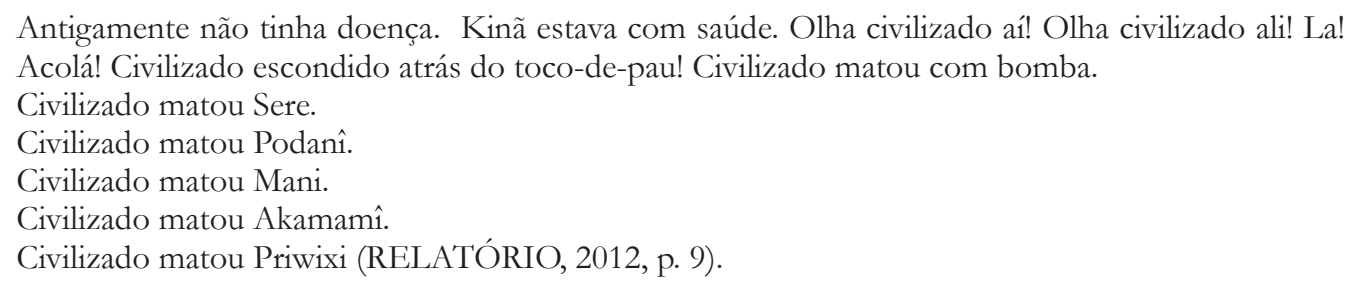

Nesse sentido, a experiência etnográfica vivida por Egydio Schwade na aldeia Yawará, foi fundamental para que fatos como esse viessem à tona, através do estímulo da memória indígena. Vale destacar que o projeto educacional proposto, centrado na articulação entre saberes e ação política, estava ancorado na obra de Paulo Freire (1985), para quem o processo de alfabetização caracteriza-se basicamente como um projeto político, garantindo o direito do educando de afirmar sua própria voz. Sendo assim, o autor não criou categorias permanentes, elas são sensíveis à problemática de categorias utilizam suas experiências de vida.

Assim, auferimos que essas experiências narradas pelos missionários, partiram do campo da organização indígena, que ajudou a manter preservada a sua memória, externada como prática cultural de resistência. A valorização da memória coletiva dos índios se constitui como uma experiência ímpar destes missionários durante o período das suas práticas educativas junto a este povo. No entanto, no dizer de Maurice Halbwachs, não "se trata mais de revivê-los em sua realidade, porém de recolocá-los dentro dos quadros nos quais a história dispõe os acontecimentos, quadros que permanecem exteriores aos grupos em si mesmos, e defini-los, confrontando-os uns aos outros" (HALBWACHS, 2006, p. 86).

A esse respeito, o pesquisador nos alerta que para o historiador é preciso fixar essas memórias por escrito, pois, na medida em que não forem registradas, corre-se o risco de perdê-las. No caso da experiência dos missionários junto ao povo Waimiri-Atroari, essas lembranças ficaram confinadas ao silêncio durante muito tempo, mas foram transmitidas oralmente de geração em geração, até o momento em que houve o devido estímulo às lembranças do grupo. Por outro lado, a oralidade é fundamental para a manutenção dessas memórias, a escrita - do ponto de vista dos índios - surgiu no processo complementar a transmissão oral segundo seus costumes, elas foram produzidas no âmbito o programa de alfabetização como uma nova fonte contemporânea que serve para escrever a história desse povo, a partir de contexto genocida e tutelar por parte do Exército brasileiro, FUNAI e de grupos empresariais. Por sua vez, a FUNAI já havia expedido desde o mês de março de 1985 a autorização no 014/85, para que Egydio e Doroti pudessem realizar por um período de dois anos a pesquisa Etnológica na área indígena. Mas depois voltaria atrás por causa da repercussão do trabalho dos missionários, que aos olhos da FUNAI foram negativas.

No entanto, o que encontramos no Relatório diverge da opinião da FUNAI, pois às

práticas que são descritas no documento, denotam uma evolução muito grande no processo da alfabeti- 
zação indígena promovida pelos missionários. Além disso, o passo a passo dos fundamentos teórico-filosóficos da prática educacional missionária é evidenciado com muita propriedade por eles, como podemos observar nesta passagem abaixo:

Continua o esforço de nos explicarmos a nós e eles a si próprios, com a motivação da escrita. Eles fornecem as palavras-chaves dos seus mitos, de suas lendas e de sua história. E o próprio esforço de decodificação das mensagens nos leva também a revelar a eles alguns fatos de nosso mundo. Pouco a pouco, a cosmovisão vai-se abrindo de parte a parte, e eles e nós vamos sentindo a importância do chão, da terra para o desenvolvimento e fortalecimento de toda essa riqueza cultural, e nos sentimos dia a dia mais compromissados na luta pela sua garantia, desenvolvimento e autodeterminação. (SCHWADE; MÜLLER - CIMI/OPAN, 1986, p. 5).

Ainda de acordo com o documento, os missionários descreveram o material didático utilizado nas aulas, como lápis grafite e colorido, quadro e giz, borrachas, papel ofício e caderno. O conjunto desses materiais proporcionaram as condições necessárias para a produção da escrita indígena. Com o avanço das aulas pouco a pouco parte da história recente deste povo foi se revelando, de acordo com um artigo escrito pelo Professor José Ribamar Bessa Freire, os índios Waimiri-Atroari passaram por situações difíceis nas mãos de militares e das empresas mineradoras, alguns deles encontrando refúgio justamente na aldeia Yawará, como podemos observar em um fragmento do seu texto reproduzido abaiXO:

\begin{abstract}
Alguns sobreviventes refugiados na aldeia Yawará conviveram durante dois anos com Egydio e Doroti. Lá, todas as pessoas acima de dez anos eram órfãs, exceto duas irmãs, cuja mãe sobreviveu ao massacre. [...] A eles se somaram outros de uma lista feita por Yaba: Mawé, Xiwya, Mayede - marido de Wada, Eriwixi, Waiba, Samyamî - mãe de Xeree, Pikibda, a pequena Pitxenme, Maderê, Wairá mulher de Amiko, Pautxi - marido de Woxkî, Arpaxi - marido de Sidé, Wepînî - filho de Elsa, Kixii e seu marido Maiká, Paruwá e sua filha Ida, Waheri, Suá - pai de Warkaxi, sua esposa e um filho, Kwida - pai de Comprido, Tarakña e tantos outros. A lista é longa, os mortos têm nomes, mas às vezes são identificados pelo laço de parentesco: "a filha de Sabe que mora no Mrebsna Mudî, dois tios de Mário Paruwé, o pai de Wome, uma filha de Antônio” (FREIRE, 2014, p. 1).
\end{abstract}

\title{
Ainda de acordo com Bessa Freire:
}

Os alunos da aldeia Yawará desenharam casas e escreveram ao lado frases como: Apapa takweme apapeme batkwapa kamña nohmepa [o meu pai foi atirado com espingarda por civilizado e morreu] - escreveu Pikida, ao lado do desenho que ilustra o fato. Taboka ikame Tikiriya yitohpa. Apiyamyake, apiyemiyekî?? [Taboca chegou, Tikiria sumiu, por que? Por que?] (FREIRE, 2014, p. 1).

As representações coletivas do grupo indígena Waimiri-Atroari tomam um caráter importante, que rompe com o paradigma de tutela imposto pela FUNAI e PWA ao longo da sua historiografia recente, estas representações culturais constituem-se a partir da representação do grupo e caracterizem-se como práticas que denotavam um processo de organização e resistência em curso por parte dessa comunidade indígena. A valorização da memória Waimiri-Atroari no âmbito da alfabetização em língua materna ensejou o reforço da sua cultura e identificação, mas, nem sempre foi assim. Segundo Baines, o aprendizado do português havia impactado negativamente a sociedade Waimiri-Atroari:

Os jovens Waimiri-Atroari que se empenhavam em aprender português passaram a ridicularizar a sua própria língua, seguindo o exemplo de muitos funcionários da FUNAI que se referiam à língua indígena como "gíria", numa desvalorização constante. A linguagem de contato expressava, em si, a dominação dos Waimiri-Atroari pelos servidores e modelava esta relação. A maioria dos funcionários incorporava palavras da língua Waimiri-Atroari nesta linguagem, modifícando-as, e os Waimiri-Atroari que conviviam mais com eles seguiam estas modificações da sua própria língua. Tais erros de pronúncia, por parte dos funcionários, não eram sempre falta de capacidade de articular as palavras Waimiri-Atroari, mas sim, uma modificação, que, embora não feita com consciência linguística, era uma manifestação de desprezo. Assim, distanciavam-se dos Waimiri-Atroari, reconstruindo até a língua destes para tentar forçá-los a se submeter a seu mando e a repudiarem sua própria língua (BAINES, 1996, pp. 11-12).

O antropólogo nos remete a um período anterior a atuação do casal de missionários 
na aldeia Yawará, a atitude colonialista empregada pelos funcionários da FUNAI face à língua indígena explicitaram as manipulações que ocorreram por parte do PWA, da FUNAI e da Eletronorte, tanto antes, quanto após a expulsão de Egydio e Doroti Schwade da aldeia indígena, essa ação foi uma retaliação por causa do trabalho dos missionários junto aos índios, que a cada dia tornava-se mais revelador, como nos aponta a figura abaixo:

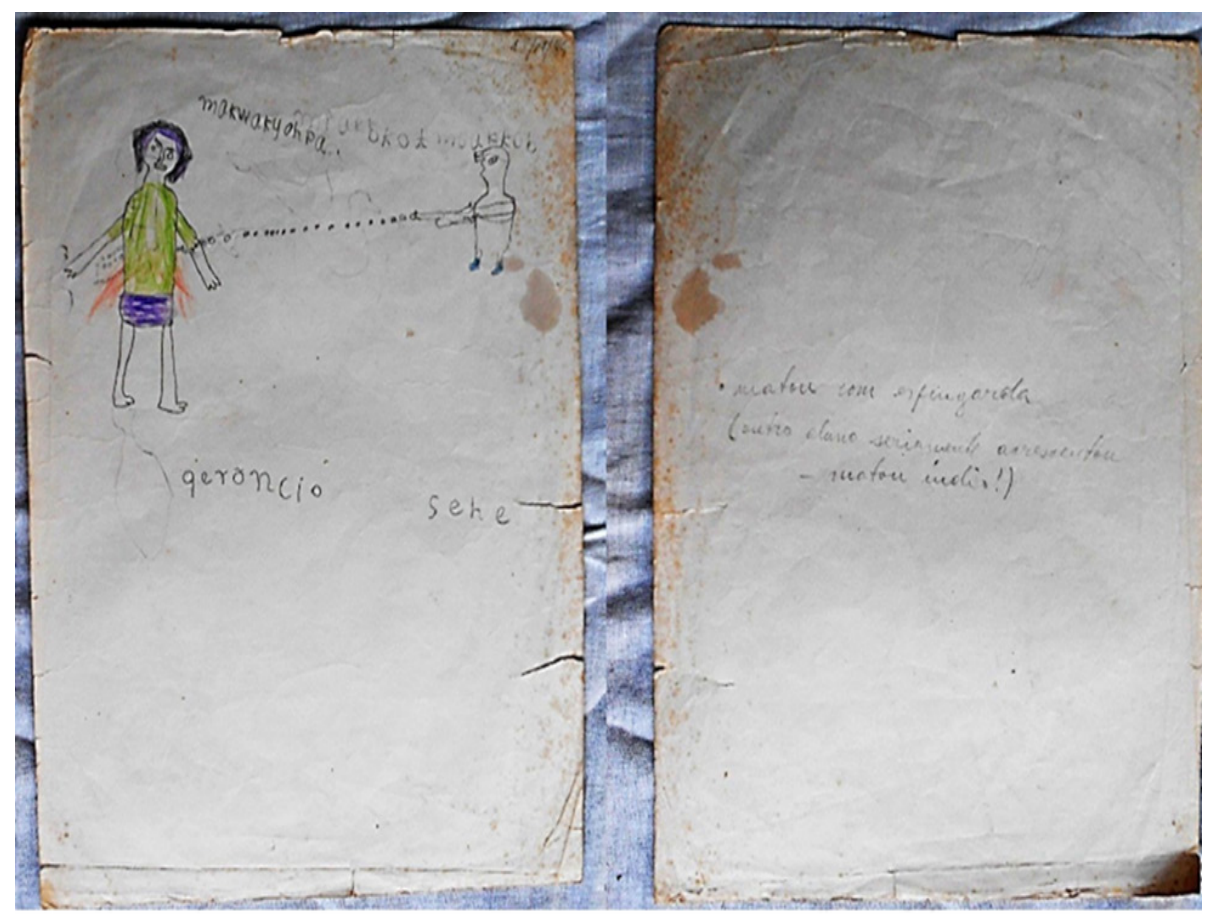

Figura 02: SEHE, Gerôncio. Desenho Kiña: Homem chorando ao ser metralhado. Escola Yawarà, 18 de novembro de 1985. Fonte: Acervo pessoal da família Schwade.

E as memórias da guerra continuavam emergindo, na medida em que as aulas avançavam:

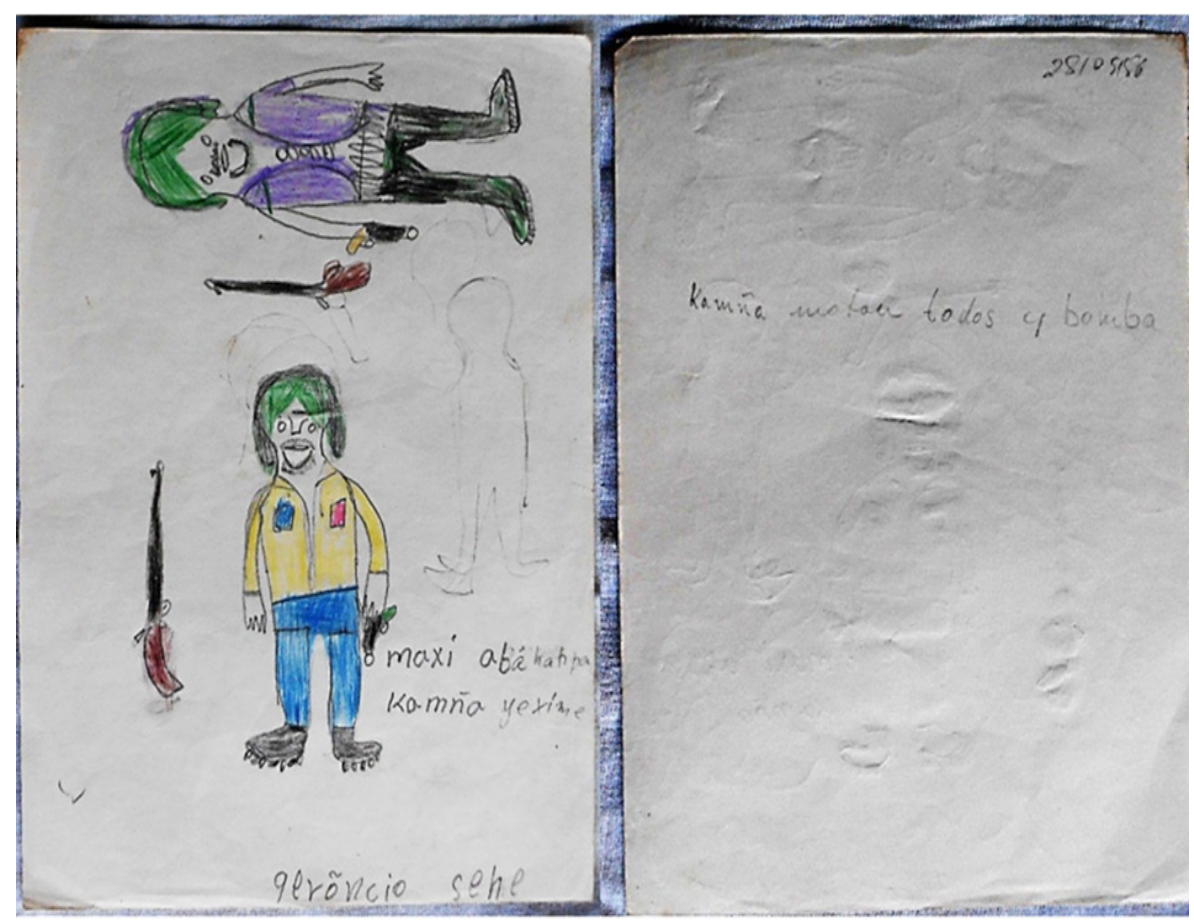

Figura 03: SEHE, Gerôncio. Desenhos Kiñá: Kamña matou todos.

Escola Yawarà, 28demaiode 1986. Fonte: Acervo pessoal da família Schwade.

MISSIONÁRIOS EXPULSOS: A INTRANSIGÊNCIA FRENTE AO INDIGENISMO DE RESISTÊNCIA. 
Fomos, quer dizer, fomos levados embora, simplesmente. Chegaram, aí [...] não, foi [...] quando veio a notícia de ordem de nos retirar, eu não [...] não nos retiramos porque eu [...] ela disse "eu queria que a programadora de ensino recebesse a escola”, né? E aí uma tardezinha, uma hora dessas mais ou menos, eles apareceram lá, um carro da FUNAI, eu tinha acabado, inclusive, de discutir com grupo de rapazes, não é, Waimiri-atroari, o primeiro livro que ia sair. E naquele mesmo dia, um dos tuxauas de uma outra aldeia vizinha, tinha trazido a sua própria filha com outros meninos para poderem estudar ali, o que mostra todo o ambiente que não tinha, ninguém, queria, e nem esperava da nossa saída, pelo contrário. Em outras aldeias no Macanaú, depois o Márcio quando começou a trabalhar lá eles não queriam que [...] eles só permitiram que ele fizesse a sua pesquisa, que ele foi como pesquisador, se ele também introduzisse a alfabetização no mesmo estilo que nós tínhamos inicializado lá em (Yawará). Quer dizer, as coisas já corriam por lá e tinha passado até também um rapaz de lá e tinha visto. Então fomos levados para fora. Inclusive, não é, o Adu era menininho, pequeno, foi eu, o Adu e a Maiá, né? (SCHWADE, 2013).

É a partir deste depoimento que Egydio Schwade começou a nos esclarecer a maneira como se deu a inesperada expulsão dele e de sua esposa Doroti Schwade da aldeia Yawará em 1986. O material etnográfico produzido pelos índios e recolhido pelo casal, demonstram claramente os massacres aos quais os índios foram submetidos durante o regime civil-militar. Por outro lado, isso parece ter desagradado em cheio a FUNAI, que desde o início da fase de atração deste povo, já se posicionara conivente a ação dos grandes projetos na terra indígena.

As práticas tutelares da FUNAI já eram conhecidas do casal de missionários, isso ficou evidente na fala de Egydio, que descreveu em entrevista a coação que ele e a sua esposa sofreram da FUNAI para deixarem a aldeia indígena, relacionando-a a construção da UHE Balbina, vejamos:

Só que num dado momento, né, em meados de 86 começou uma futricação, né, de ter essa usina, [...] alegaram que os índios queriam a nossa saída, que não queriam o Stephen, como expulsaram, queriam expulsar também o Márcio Silva, né? Tudo criação mesmo porque os índios estavam felizes. Todo tempo nós [...] inclusive um funcionário da FUNAI encarregado de fazer a [...] assim, de apresentar as motivações, o relatório da nossa expulsão, ele no final diz que a amizade que os índios tinham para conosco não significava que queriam nos ver [...] não podia negar que eles tinham. Mas pelo contrário, isso era um sintoma que em breve nos haveriam de massacrar porque esse era o costume deles (SCHWADE, 2013).

Essas justificativas dadas pelos funcionários da FUNAI tentavam criar novamente a imagem dos Waimiri-Atroari como "matadores de branco". Todavia elas não poderiam servir de parâmetro para justificar ações dos missionários nas terras indígenas, já que pelos relatos descritos pelos próprios missionários esta relação era amigável. Portanto, isso se configura muito mais como uma estratégia por parte da FUNAI para tentar quebrar a aliança dos índios com os missionários, do que propriamente uma possível ação dos indígenas. De acordo com Egydio, um dos motivos mais fortes da época para que a FUNAI fosse contrária a sua permanência na aldeia era construção da Hidrelétrica de Balbina, nesse sentido, o pesquisador do INPA Philip Fearnside, publicou um artigo criticando abertamente Balbina, como podemos observar logo abaixo:

Balbina é um dos projetos conhecidos no Brasil como "obras faraônicas". Assim como as pirâmides do antigo Egito, estas maciças obras públicas exigem os esforços de uma sociedade inteira para se completar, apesar de não trazer praticamente nenhum retorno econômico. Mesmo que as estruturas sejam simplesmente construídas e abandonadas, elas servem a interesses de curto prazo dos envolvidos, desde as firmas que recebem contratos de construção até políticos que querem para os seus distritos empregos e facilidades comerciais gerados pelos projetos durante a fase de construção. (FEARNSIDE, 1990, p. 11).

Como vimos, muito embora este tenha sido um dos motivos pelos quais os missionários foram expulsos, outra versão surgiu com intensidade e foi divulgada de forma oficial pela FUNAI através de uma comunicação interna, que atribuiu à saída prematura dos educadores ao "suposto" desejo das lideranças indígenas.

No entanto, os argumentos utilizados pela FUNAI no documento, procuram desca- 
racterizar a imagem de resistência indígena, apresentada pelos próprios índios durante as aulas, como veremos a seguir. "Supomos que esta maneira de passar os fatos aos índios, que em sua maioria são sonhadores e fantasiosos, tenha sido à base do descontentamento contra o Sr. Egydio por parte dos líderes Atroari...” (COMUNICAÇÃO 41/86, 1986, p. 2. Grifo meu).

Em resposta a esse documento, o casal Egydio e Doroti Schwade escreveu alguns comentários demonstrando a sua perplexidade com as declarações dadas pelo Sr. Raimundo Nonato Corrêa, que na época era o responsável pelo Núcleo de Apoio Waimiri-Atroari - NAWA, apontando-o segundo eles como um homem "grosseiro, traiçoeiro, subserviente e cínico" (COMENTÁRIO, 1987, p. 1). Ainda de acordo com os missionários, sua estadia na aldeia com seus quatro filhos pequenos, serviria para atestar a boa relação que eles mantinham com os índios, além disso, contribuiria desconstruir a imagem passada pela FUNAI, que os índios eram hostis ao homem branco. Isso pode ser observado em um fragmento do comentário logo abaixo:

\begin{abstract}
tudo isso obedece à mesma tática, tantas vezes utilizada pelas autoridades da FUNAI, de denegrir a imagem desses índios para acobertar a verdadeira história dos 20 anos de FUNAI junto a este povo e sustenta a política que vai sistematicamente entregando aos interesses empresariais capitalistas o patrimônio e as próprias terras dos Waimiri-atroari. Esses, sim, porque estão em sintonia com a FUNAI, penetram diariamente, "sem perigo", pelo território Waimiri-Atroari (COMENTÁRIO, 1987, p. 2).
\end{abstract}

Outra acusação levantada pelo Sr. Nonato a Egydio Schwade, e utilizada como argumento para a sua expulsão, trata-se do seu contato que ocorreu com um grupo de holandeses que visitaram a aldeia Yawará em outubro de 1986. Como eles falavam alemão, Egydio acabou sendo o interlocutor do grupo, haja vista que durante os anos de estudos que ele passou para se tornar padre houve o contato com diversas línguas, além do fato dele ser proveniente da região sul do país e ter convivido com vários imigrantes de outras nacionalidades.

Porém, Egydio foi acusado de distorcer as traduções dos visitantes e isso segundo o Sr. Nonato, teria desagradado o líder dos Waimiri-Atroari, na época o índio Viana. Todavia, no mesmo documento, Egydio se defende de tais acusações, alegando ter sido o mais fiel possível à tradução do grupo de holandeses. Apesar do clima evidentemente desfavorável, Egydio e Doroti continuaram com o trabalho de alfabetização junto aos índios, e os relatos de ataques versus resistência, a cada dia tornavam-se mais latentes, como podemos observar na figura abaixo:

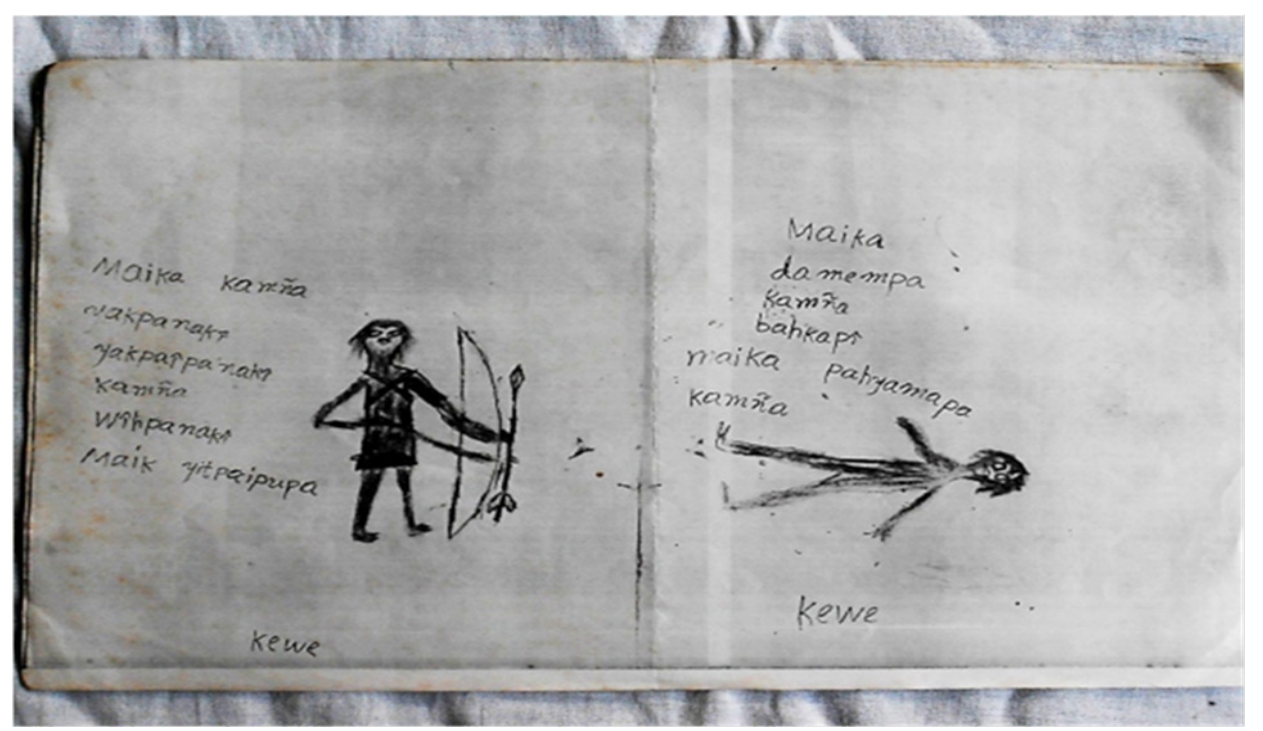

Figura 04: KEWE, Claudio. Desenho Kiña. Maiká Kamña Nakpanakî. Yawará, s/d. Fonte: Acervo pessoal da família Schwade. 
A representação acima demonstra a maneira como os índios resistiram ao avanço dos brancos -(kamña)- em suas terras. Empunhando um arco e flecha, Maika representa um guerreiro Waimiri-Atroari contra "civilizado branco".

No final do ano de 1986, o casal Schwade foi surpreendido com a chegada de membros da FUNAI, que os retiram de maneira abrupta da aldeia indígena, inclusive na presença dos seus filhos pequenos, como nos relatou Egydio em entrevista. "Então fomos levados para fora. Inclusive, não é o Adu era menininho pequeno, fui eu o Adu e a Maiá, né? Eles ficaram atrás. Angeli e o Maiká bebezinho, ficaram na frente, na cabine, né?” (SCHWADE, 2013).

A partir daí, a repercussão do episódio da expulsão dos missionários da aldeia indígena, ganharia as páginas de alguns periódicos da época, que noticiaram o fato abordando tanto a visão dos próprios missionários, quanto à do CIMI. Nesse sentido, a matéria publicada na edição de 21 de dezembro de 1986 do Jornal A Crítica, abriu espaço para que Egydio e Doroti Schwade se pronunciassem publicamente sobre o fato ocorrido.

O verdadeiro motivo é porque temos alertado as lideranças indígenas para o perigo que representam as mineradoras na região, principalmente a Paranapanema, que sistematicamente saqueia a área indígena, reduzindo assim seu patrimônio (A CRÍTICA, 21/12/1986).

Esse mesmo jornal publicou uma nota oficial do CIMI Norte I, onde constava a insatisfação perante o fato, como veremos a seguir:

a expulsão de Egydio e Doroti da área indígena Waimiri-Atroari não se deve nem à vontade dos índios e nem pode ser atribuída à falta de competência no trabalho. O motivo de encontra na total capitulação da FUNAI, frente aos grandes interesses econômicos que se vêm instalando na área indígena (A CRÍTICA, 21/12/1986).

Enquanto isso, a expulsão continuava rendendo manchetes aos jornais da época, em uma delas, publicada em uma edição do Jornal A Notícia de Manaus, trazia o seguinte tema: "Missionários expulsos: CIMI diz que FUNAI capitulou frente aos grupos econômicos”, (A Notícia, 24/12/1986). Na matéria, o CIMI defendeu a postura dos missionários e reafirmou o seu papel de alfabetizar os índios.

A postura dos periódicos publicados em Manaus sobre o caso da expulsão dos missionários mostrou-se diferente da abordagem dada por outros periódicos que foram publicados em outros Estados na época. Isso fica mais claro, quando comparamos duas reportagens distintas sobre o assunto, a primeira delas, publicada novamente pelo Jornal A Notícia de Manaus com a seguinte matéria: "Retirada compulsória: missionário denuncia política entreguista do Governo Federal”. Nessa matéria Egydio Schwade afirmou categoricamente que:

“O verdadeiro motivo de nossa retirada compulsória da área indígena, é o incômodo que causamos à política entreguista do Governo, que viola a política indigenista oficial expressa na Constituição e no Estatuto do Índio" (A Notícia, 21/12/1986).

No entanto, alguns meses depois do fato, o Jornal O Estado de São Paulo, inverteu totalmente de forma leviana esta perspectiva, ao publicar a seguinte matéria, "Padre incentiva índios contra civilizado"(O ESTADO DE SÃO PAULO, 06/10/1987). Na matéria o jornal alegou que Egydio utilizava-se de uma cartilha para tentar doutrinar os índios e mantê-los longe dos civilizados. Porém, o jornal apenas teve acesso a um Relatório que foi produzido pela FUNAI, diga-se de passagem, de forma bastante tendenciosa e arbitrária, na medida em que ela estava atrelada à Eletronorte e não aos interesses dos índios, colocando-os como vitimizados na situação, tentando inverter a sua perspectiva de resistência. A própria FUNAI já vinha sendo alvo de profundas críticas por parte da comunidade indigenista, isso pode ser confirmado a partir de um trecho analisado de uma carta enviada por uma amiga do casal 
Schwade residente no Rio de Janeiro chamada Beth [sic], que era militante da causa indígena, vejamos:

O que havia de bom na FUNAI em termos de profissionais competentes e leais aos índios foram sumariamente demitidos, restando apenas à escória. [...] Acho que as intenções dessa "nova FUNAI" (que é mais velha que qualquer outra coisa) não são das melhores, principalmente no que diz respeito aos índios e seus territórios. O clima de terrorismo e espionagem está terrível, acho que pior do que no "tempo dos coronéis" (CARTA, 01/10/1985).

Nesse sentido, verifica-se que a FUNAI não passava a menor credibilidade para tentar desabilitar o trabalho dos missionários, que por sua vez, já haviam passado todos os seus fundamentos teórico-filosóficos, assim como os assuntos abordados em sala de aula via carta para a Superintendente Regional da FUNAI, Profa. Zoraide Goulart dos Santos como veremos abaixo:

[...] iniciamos em 04 de setembro de 1985, os trabalhos na escola da aldeia Yawará. [...] trata-se da primeira iniciativa de um projeto de educação bilíngue em área indígena Waimiri-Atroari. [...] Na elaboração do sistema ortográfico que utilizamos na escola, valemo-nos de consultas a linguistas profissionais, afiliados não apenas à FUNAI/AESP, mas ainda a centros universitários de pesquisa como a UFRJ e a UA (CARTA, 14/12/1986).

A partir da análise do documento, pudemos constatar que além de preparados para exercer a docência junto ao povo Waimiri-Atroari, o casal de missionários também se preocupou em manter o diálogo com o órgão indigenista, sendo assim, não havia motivos plausíveis para o ataque irresponsável que foi feito pelo jornal na época. O episódio da expulsão dos missionários ainda repercutiu por muito tempo, e ainda hoje é objeto de análise dos que se debruçam sobra à política indigenista de resistência frente aos desmandos e intransigências do poder institucional.

\title{
WRITING WAIMIRI-ATROARI, AN ETHNOGRAPHY OF INDIGENOUS ETHNOLOGY: MEMORIES AND CONSTRUCTION SOCIAL RESISTANCE
}

\begin{abstract}
The purpose of this work is to approach from a ethnographic experience lived by a missionary couple linked to the Catholic Church between 1985 and 1986 together with the Waimiri-Atroari Indians in Yawara village in Roraima, the production of written based sources the reconstruction of memory and some oral accounts of this group. In the context of history, are still scarce, so far, in Brazil related studies more depth to this theme, still far from if you want to get a definitive answer on this issue, the paper aims to highlight some theoretical and methodological aspects related to work of missionaries, which were based on Paulo Freire method to try to alphabetize indigenous furthermore oral statements made years later by one of the missionaries corroborate the memories of that time, where the Indians produced a new type of source, based on a fateful genocidal experience lived by them during the civil-military regime, but which demonstrated the social organization of the group, and be characterized as a form of cultural resistance.
\end{abstract}

\section{KEYWORDS}

Waimiri-Atroari Indians. Memory. Missionary work. Resistance.

\section{REFERÊNCIAS}

AUTORIZAÇÃO da FUNAI n. 014/85, que concedeu autorização para Egydio e Doroti Schwade fazerem pesquisa Etnológica na área indígena Waimiri-Atroari, em 05 de março de 1985.

BAINES, S. G. O impacto da escrita na sociedade Waimiri-Atroari. Cadernos de Linguagem e Sociedade, 2 (l) 1996. CARTA para Egydio e Doroti escrita por sua amiga Beth, residente no Rio de Janeiro. Rio de Janeiro, 01 de outubro de 1985.

CARTA para Zoraide Goulart dos Santos. (CIMI/OPAN/FUNAI). Presidente Figueiredo, 14 de dezembro de 1986.

COMENTÁRIO de Egydio e Doroti Schwade, sobre o relatório do Sr. Raimundo Nonato Corrêa em 1987.

COMUNICAÇÃO INTERNA n. 41/86, feita pelo coordenador do NAWA/FUNAI, o Sr. Raimundo Nonato Corrêa, sobre o Relatório a respeito da saída de Egydio Schwade da área Waimiri-Atroari, em 30 de dezembro de 1986. 
ENTREVISTA realizada com Egydio Schwade, em sua casa em Presidente Figueiredo, às margens da BR 174, no dia 18 de outubro de 2013.

FEARNSIDE, P. M. A Hidrelétrica de Balbina: o faraonismo irreversível versus o meio ambiente na Amazônia. São Paulo: Instituto de Antropologia e Meio Ambiente, 1990.

FREIRE, J. R. B. As Malocas da Praça de Maio. Artigo publicado no Sítio Oficial Taqui Pra Ti, no dia 06 de junho de 2014. Disponível em: http://goo.gl/JVXI35. Acesso em: 07 de junho de 2014.

FREIRE. P. Pedagogia do oprimido. Rio de Janeiro: Paz e terra, 1985.

HALBWACHS, M. A Memória Coletiva. São Paulo: Ed. Centauro, 2006.

JORNAL A CRÍTICA. Alerta. Professores confessam a Causa do Afastamento. Manaus, 21 de dezembro de 1986. JORNAL A NOTÍCIA. Missionários expulsos. CIMI diz que FUNAI capitulou frente aos grupos econômicos. Manaus, 24 de dezembro de 1986.

JORNAL A NOTÍCIA. Retirada compulsória: missionário denuncia política entreguista do Governo Federal. Manaus, 21 de dezembro de 1986.

JORNAL O ESTADO DE SÃO PAULO. Padre incentiva índios contra os civilizados. São Paulo, 06 de outubro de 1987.

PORTARIA n. 1898, assinada pelo Presidente em exercício da FUNAI Gerson da Silva Alves, que autorizou a criação de um grupo de estudos indigenistas, em 03 de julho de 1985.

RELATÓRIO DO COMITÊ ESTADUAL DA VERDADE. O genocídio do povo Waimiri-Atroari. Manaus, 2012, $92 \mathrm{p}$.

RICOEUR, P. A memória, a história, o esquecimento. Tradução de Alain François. Campinas, SP: Editora da UNICAMP, 2007.

SCHWADE, E. \& SCHWADE, D. A. M. (CIMI/OPAN). Relatório da $1^{a}$ Experiência de alfabetização entre os Waimiri-Atroari. Presidente Figueiredo, 15 de dezembro de 1986.

SCHWADE, E. \& SCHWADE, D. A. M. A Escola indígena e o ABC. Aldeia Yawará, julho de 1986.

SCHWADE, E. Doroti Alice Müller Schwade: Recordação no seu terceiro ano de falecimento. Artigo publicado no Blog da Casa da Cultura do Urubuí em 03 de dezembro de 2013. Disponível em: http://goo.gl/sA8TSU. Acesso em: 21 de fevereiro de 2015. 